\title{
THE SWINE FLU VACCINE AND GUILLAIN-BARRÉ SYNDROME: A CASE STUDY IN RELATIVE RISK AND SPECIFIC CAUSATION
}

\author{
DAVID A. FREEDMAN* AND PHILIP B. STARK**
}

INTRODUCTION

This article discusses the role of epidemiologic evidence in toxic tort cases, focusing on relative risk. If a relative risk is above 2.0, can we infer specific causation? Relative risk compares groups in an epidemiologic study. One group is exposed to some hazard, like a toxic substance; another "control" group is not exposed. For present purposes, relative risk is a ratio:

$$
\mathrm{RR}=\text { Observed/Expected }
$$

The numerator in this fraction is the number of injuries observed in the exposed group. The "expected" number in the denominator is computed on the theory that exposure has no effect, so that injury rates in the exposed group should be the same as injury rates in the control group. Adjustments are often made to account for known differences between the two groups, for example, in the distribution of ages.

The basic intuition connecting relative risk and probability of causation can be explained as follows. Suppose that the exposed and unexposed groups in an epidemiologic study are similar except for the exposure of interest, so that confounding is not an issue. For simplicity, suppose also that the two groups are the same size. To have specific numbers, suppose there are 400 injuries in the exposed group and 100 in the control group. In other words, the observed

\footnotetext{
Copyright (C) 2001 by David A. Freedman and Philip B. Stark

This article is also available at http://www.law.duke.edu/journals/64LCPFreedman.

* Professor of Statistics, University of California at Berkeley.

** Professor of Statistics, University of California at Berkeley.

We would like to thank the following persons for useful discussions: Michael Berger, Richard Berk, Joe Cecil, John Conley, Mike Finkelstein, Mike Green, Angelika Hahn, Paul Humphreys, James Robins, and Larry Schonberger. Many of the participants in the case shared their knowledge with us, including some of the epidemiology experts (Leonard Kurland, Nathan Mantel, and Neal Nathanson), and the lawyers who presented the epidemiologic evidence (Leslie Ohta and Charles Thomas). The Department of Justice provided surviving portions of the trial transcript. Part of this work was completed while Philip B. Stark was on appointment as a Miller Research Professor in the Miller Institute for Basic Research in Science.
} 
number of injuries is 400 , compared to an expected number of 100 . The relative risk is 400/100, or 4. Without exposure, there would be only 100 injuries among the exposed, so 300 of the 400 injuries may be attributable to the exposure and 100 to other factors. Apparently, then, each injury in the exposed group has a chance of $3 / 4$ of being caused by exposure. Likewise, a relative risk of 3 corresponds to a chance of $2 / 3$, while a relative risk of 2 corresponds to a chance of $1 / 2$, which may be the minimum level needed to carry the burden of proof in civil litigation. ${ }^{1}$

The object here is to explore the scientific logic behind these intuitions. Of course, any epidemiologic study is likely to have problems of bias: Uncontrolled confounding appears to be the rule, rather than the exception. ${ }^{2}$ When effects are large, such problems may not be material. When relative risk is near the critical value of 2.0 , potential biases must be assessed more carefully. Individual differences also play an important role: The plaintiff may not resemble typical members of the study population; effects of such differences need to be considered. This is a salient difficulty in connecting relative risk to specific causation. With a randomized controlled experiment, for example, treatment and control groups are balanced in the aggregate but not at the level of individuals. Thus, even with the best research designs-where general causation is easily demonstrated-specific causation remains troublesome.

We wanted to consider such issues in the context of a real example, in part to see how well the courtroom evidence stands up when examined retrospectively. We started from a list of legal opinions where relative risk and specific

1. For previous discussions from various perspectives, see Cimino v. Raymark, 151 F.3d 297, 30102 (5th Cir. 1998); H.L.A. HART \& TONY HONORÉ, CAUSATION IN THE LAW 104 (2d ed. 1985) (discussing "but for" causation); American Medical Association, Council on Scientific Affairs, Radioepidemiological Tables, 257 JAMA 806 (1987); Bert Black \& David E. Lilienfeld, Epidemiologic Proof in Toxic Tort Litigation, 52 FordHAM L. REV. 732 (1984); Michael D. Green et al., Reference Guide on Epidemiology, in REFERENCE MANUAL ON SCIENTIFIC EVIDENCE 333, 381-86 (Federal Judicial Ctr. ed., 2d ed. 2000); David H. Kaye \& David A. Freedman, Reference Guide on Statistics, in REFERENCE MANUAL ON SCIENTIFIC EVIDENCE, supra at 83, 96-97 n.38; Diana B. Petitti, Book Review, Reference Guide on Epidemiology, 36 JuRIMETRICS J. 159 (1996); James M. Robins \& Sander Greenland, The Probability of Causation Under a Stochastic Model for Individual Risk, 45 BIOMETRICS 1125 (1989); see also In re Fibreboard, 893 F.2d 706, 712 (5th Cir. 1990) (footnotes, citations, italics, and internal quotation marks omitted):

It is evident that these statistical estimates deal only with general causation, for populationbased probability estimates do not speak to a probability of causation in any one case; the estimate of relative risk is a property of the studied population, not of an individual's case. This type of procedure does not allow proof that a particular defendant's asbestos really caused a particular plaintiff's disease; the only fact that can be proved is that in most cases the defendant's asbestos would have been the cause.

2. Confounding means that the exposed and unexposed groups in a study differ systematically on factors related to the probability of injury. Confounding leads to bias in estimated relative risk, when the calculation of the expected number of injuries among the exposed fails to reckon with these systematic differences: For example, measurements may not be available on some important confounder, or the impact on risks may be underestimated. For discussion and citations to the literature, see David Freedman, From Association to Causation: Some Remarks on the History of Statistics, 14 STAT. SCI. 243 (1999); Kaye \& Freedman, supra note 1, at 90-97. 
causation come together. ${ }^{3}$ Generally, the evidence of harm was shaky. In one case-Manko v. United States ${ }^{4}$ - there turned out to be a substantial body of epidemiologic evidence suggesting that the swine flu vaccine caused GuillainBarré syndrome ("GBS"). Moreover, the vaccine campaign of 1976 is itself a fascinating case study of specific causation.

GBS is a rare neurological disorder, sometimes triggered by vaccination or by infection. Paralysis can follow, although most patients make a complete recovery in a few weeks or months. The epidemiology of swine flu vaccine and GBS is summarized in Part II. Part III discusses Manko and the use of relative risk to demonstrate specific causation. Although the plaintiff prevailed, his proof of specific causation seems questionable, due in part to differences between him and typical members of the study population.

There is a simple probability model where intuitions about relative risk and causation can be analyzed. The model sets aside all problems of confounding and bias, and considers only difficulties created by individual differences. For any particular plaintiff, the probability of causation is not identifiable from the data. Even the average probability of causation can be much lower than intuition suggests. For instance, if four percent of the exposed group suffers injury compared to one percent among the unexposed, the relative risk is 4 and the probability of causation would seem to be $3 / 4$; but the average probability of causation can be as low as three percent, the difference in injury rates. ${ }^{5}$

II

\section{THE SWINE FLU VACCINE AND GBS}

This section reviews the swine flu vaccination campaign of 1976 and the epidemiology of GBS, as background for the discussion of Manko. The story opens in 1918, with an influenza pandemic that killed some twenty million people worldwide. In February 1976, a soldier in training at Fort Dix, New Jersey, died of influenza; the virus turned out to be similar in antigenic type to the 1918 virus. With public health professionals at the Centers for Disease Control

3. Provided by Mike Green; see also Green et al., supra note 1, at 384 n.140; Kaye \& Freedman, supra note 1 , at $96-97$ n.38.

4. 636 F. Supp. 1419 (W.D. Mo. 1986), aff'd in part, 830 F.2d 831 (8th Cir. 1987). In other cases with fact patterns similar to Manko, the defendant prevailed. See, e.g., Alvarez v. United States, In re Swine Flu Litig., 495 F. Supp. 1188 (D. Colo. 1980); Lima v. United States, 508 F. Supp. 897 (D. Colo. 1981). There is a useful summary of the medical and legal background in Alvarez, 495 F. Supp. at 119091, 1194-96.

5. Intuitive arguments for probability of causation in effect assume uniformity of risk across people, or random selection of persons. By contrast, our probability model views some people as more susceptible to injury than others; each individual has his or her own probability of causation, namely, the probability of not being injured if unexposed, conditional on having been exposed and injured. The average of these individualized probabilities is small when most of the injuries due to exposure are likely to occur in a relatively small subgroup of the exposed population. Furthermore, the probability of bringing suit may vary with susceptibility to injury, a relationship that is also considered in the model. The present article is adapted from David A. Freedman \& Philip B. Stark, The Swine Flu Vaccine and Guillain-Barré Syndrome: A Case Study in Relative Risk and Specific Causation, 23 EVALUATION REV. 619 (1999). The probability model is developed in an appendix to that paper. 
("CDC") taking the lead, the federal government organized a massive immunization campaign. Vaccination began on October 1, 1976. The vaccine was targeted at the 151 million people age 18 and over; some 43 million were eventually vaccinated. Beyond the initial cluster at Fort Dix, however, only a handful of additional cases materialized, and several public health figures wanted the campaign stopped. A moratorium was declared on December 16, 1976-in part because an epidemic seemed increasingly unlikely, and in part because there were sporadic reports of GBS cases following vaccination. ${ }^{6}$

The CDC set up a nationwide surveillance system to collect case reports on GBS from state health authorities, who in turn worked with local authorities, hospitals, and doctors. Using these data, Alexander D. Langmuir and colleagues analyzed the incidence rate of GBS among the vaccinated, by weeks since vaccination. This rate is shown as the highly peaked solid line in panel (a) of Figure $1 .^{8}$ Rates are "per million person-weeks" of observation; these are incidence rates, not relative risks. (Ten persons followed for one week count as ten person-weeks of observation; so does one person followed for ten weeks; the incidence rate is the number of new cases during a week, divided by the number of persons observed that week.)

Shown for comparison is the incidence rate of GBS among the unvaccinated, by calendar week from October 1 (lower broken line). Two time scales are involved: weeks from vaccination to onset for the vaccinated group, and weeks from start of program to onset for the unvaccinated. The sizes of the vaccinated and unvaccinated populations change rapidly over time, due to the vaccination campaign. Size is taken into account in computing the rates through adjustments to the denominator-the number of person-weeks of observation. ${ }^{9}$

Panel (a) in Figure 1 shows that for some weeks after vaccination, the incidence rate of GBS rises sharply, becoming much larger than the background

6. For two different accounts of the vaccine campaign, see RICHARD E. NEUSTADT \& HARVEY

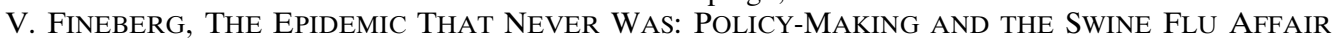
(1981); Arthur M. Silverstein, Pure Politics And Impure SCIEnCE: THE Swine Flu AfFair (1981). The latter was written to correct the former, but there is broad agreement on the central points. See also Gina Kolata, Flu (1999).

7. See Alexander D. Langmuir et al., An Epidemiologic and Clinical Evaluation of Guillain-Barré Syndrome Reported in Association with the Administration of Swine Influenza Vaccines, 119 AM. J. EPIDEMIOLOGY 841 (1984); see also Alexander D. Langmuir, Guillain-Barré Syndrome: The Swine Influenza Virus Vaccine Incident in the United States of America, 1976-77: Preliminary Communication, 72 J. ROY. SOC'Y MED. 660 (1979); Lawrence B. Schonberger et al., Guillain-Barré Syndrome Following Vaccination in the National Influenza Immunization Program, United States, 1976-1977, 110 AM. J. EPIDEMIOLOGY 105 (1979).

8. All computations are ours. Data are from Langmuir et al., supra note 7. See Freedman \& Stark, supra note 5, app. B.

9. Langmuir et al. had data covering the time from October 2, 1976 to January 31, 1977, subdivided into 17 "periods." A period is generally a week in duration, but period one is nine days long and period 17 is eight days long. The length of the period is taken into account when computing person-weeks of observation. The horizontal scale for the background rate in Figure 1(b) should really be labeled "calendar period" rather than "calendar week." The number of GBS cases, vaccinated and unvaccinated, was determined through the CDC's surveillance program. See Langmuir et al., supra note 7. 
rate. Later, there is a reversion to background levels. In other words, there is a clear association between vaccination and GBS, provided the onset of GBS is within a few weeks of vaccination.

FIGURE 1: Panel (a) shows the incidence rate among the vaccinated, by week since vaccination (highly peaked solid line). This rate is compared to the background rate (lower broken line) among the unvaccinated, by week since the start of vaccination campaign. Two time scales are involved. The moratorium occurred in the 11th week after the start of the campaign, indicated by a vertical line. Panel (b) shows the background rate in more detail, both truncated and raw. (The "truncated" background rate is prevented from falling below a lower bound of 0.24 cases per million person weeks.)

Is the association causal? That is still controversial. No excess risk for GBS was observed in the military, or with previous vaccines much like the swine flu vaccine. Further arguments and counter-arguments will not be discussed here..$^{10}$

10. See, e.g., Angelika F. Hahn, Guillain-Barré Syndrome, 352 LANCET 635 (1998); see also Richard A.C. Hughes, Guillain-BarRé Syndrome 103 (1990); Allan H. Ropper et Al., GuILlAIN-BARRÉ SYNDROME 28-29, 67 (1991); Ettore Beghi et al., Guillan-Barré Syndrome: Clinicoepidemiologic Features and Effect of Influenza Vaccine, 42 ARCHIVES OF NEUROLOGY 1053 (1985); Richard A.C. Hughes \& Jeremy H. Rees, Clinical and Epidemiologic Features of Guillain-Barré Syndrome, 176 J. INFECTIOUS DISEASES S92 (Supp. 2 1997) (finding the evidence less ambiguous than do other authors); Leonard T. Kurland et al., Swine Influenza Vaccine and Guillain-Barré Syndrome. Epidemic or Artifact?, 42 ARCHIVES OF NeUROLOGY 1089 (1985); Thomas J. Safranek et al., Reassessment of the Association Between Guillain-Barré Syndrome and Receipt of Swine Influenza Vaccine in 19761977: Results of a Two-State Study, 133 AM. J. EPIDEMIOLOGY 940 (1991).

In subsequent mass vaccinations, excess risk is minimal, although statistical significance is achieved if data for 1992-93 and 1993-94 are pooled. See Tamar Lasky et al., The Guillain-Barré Syndrome and the 1992-1993 and 1993-1994 Influenza Vaccines, 339 NEW ENG. J. MED. 1797 (1998); see also Eugene S. Hurwitz et al., Guillain-Barré Syndrome and the 1978-1979 Influenza Vaccine, 304 NEW ENG. J. 
(A) INCIDENCE OF GBS AMONG

VACCINATED (HIGHLY PEAKED SOLID LINE) UNVACCINATED (LOWER BROKEN LINE)

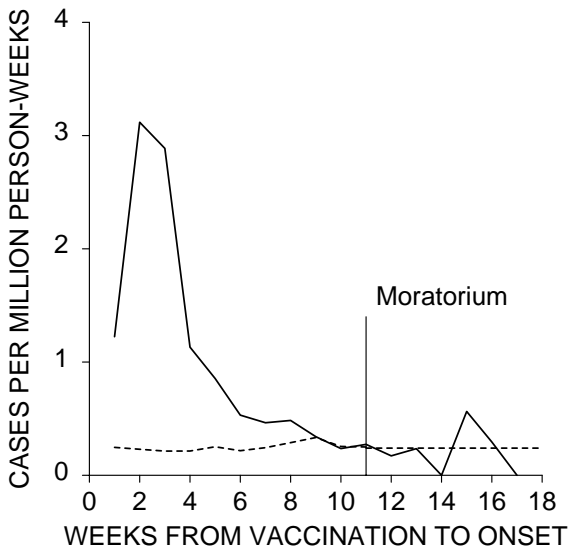

(B) INCIDENCE OF GBS AMONG UNVACCINATED VERTICAL SCALE IS MAGNIFIED TENFOLD

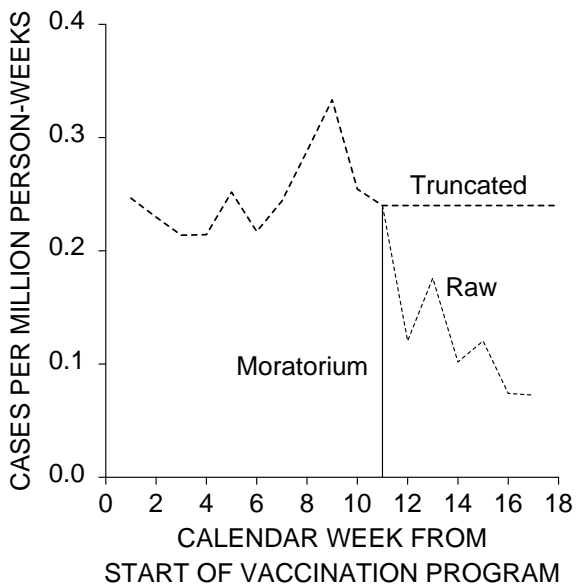


After reviewing the data and the literature, we think that a finding of general causation is reasonable: On balance of evidence, the swine flu vaccine could well have increased the risk for GBS for a period of several weeks after vaccination.

The background rate in Figure 1(a) is shown on a magnified scale in panel (b). After the moratorium, there is a precipitous drop in the "raw" (that is, reported) background rate. This drop is best explained as an artifact of data collection. After the moratorium, it seems probable that GBS was less in the news, neurologists were less likely to make the diagnosis among unvaccinated persons, and state health departments were less diligent in collecting the data and reporting to $\mathrm{CDC}$.

The background rate of GBS (that is, the rate among unvaccinated persons) is a critical baseline statistic, because the incidence rate of GBS among the vaccinated persons is compared to this baseline in Figure 1 and in computations of relative risk. GBS is not a reportable disease, nor is the diagnosis easy. Thus, considerable uncertainty attaches to the background rate. Langmuir et al. did not believe the background could be below 0.24 per million person-weeks. ${ }^{12}$ Following their lead, Figure 1(a) takes the background rate as 0.24 after the moratorium ("truncation"). The lower broken line is horizontal after week eleven. Current literature suggests a background rate of 0.2 to 0.4 per million person-weeks, with only minor seasonal variation-confirming the estimates of Langmuir et al. ${ }^{13}$

Another feature of the data analysis in Langmuir et al. will be relevant. They distinguish between cases with extensive and limited paralysis: ${ }^{.14}$ The association is strong for the extensive cases, but they found little evidence of asso-

MED. 1557 (1981); Jonathan E. Kaplan et al., Guillain-Barré Syndrome in the United States, 1979-1980 and 1980-1981: Lack of an Association with Influenza Vaccination, 248 JAMA 698 (1982).

If the hypothesis of causation is rejected, the patterns in Figures 1 and 2 are explicable as statistical artifacts. GBS is not easily distinguished from certain other neurological conditions. The publicity about swine flu and GBS could increase the reporting rate, and there would be more of a tendency for ambiguous cases following vaccination to be classified as GBS by comparison with similar cases among the unvaccinated.

11. Larry Schonberger, who was doing surveillance at the CDC, reports that a number of states put significantly less effort into data collection after the moratorium. Telephone Interview with Larry Schonberger; see also Schonberger et al., supra note 7, at 197. Some of the drop may also be due to increasing delays in reporting cases to the CDC.

12. See Langmuir et al., supra note 7, at 856-59. In the classification used by Langmuir et al., cases of type A and B have "extensive" paralysis, type C and D are "limited," while type E means "insufficient information." See id. Langmuir et al. give lower bounds of 0.14 and 0.07 for cases with extensive and limited paralysis; we have added 0.03 for cases with insufficient information, computed from data in their Table 8. See Freedman \& Stark, supra note 5, app. B, for more detail on background rates and the calculations in Figures 1 and 2.

13. See Hughes, supra note 10, at 101; RopPer ET AL., supra note 10, at 19; Hahn, supra note 10, at 635. But see Lasky et al., supra note 10 (finding a rate of about 0.15 per million person-weeks). A rate of 0.24 per million person-weeks translates to one case per 100,000 persons per year, approximately; both scales are used in the literature. Certain forms of GBS, rare in North America but prevalent elsewhere, do show seasonal variation.

14. See Langmuir et al., supra note 7. 
ciation for the limited cases. ${ }^{15}$ A change in the legal situation should also be noted. Before the 1976 swine flu campaign got underway, the insurance companies refused to issue coverage for adverse events resulting from vaccination, and the drug companies refused to produce the vaccine without coverage. To resolve this impasse, the federal government accepted liability. ${ }^{16}$ Thus, GBS victims applied for compensation not to the vaccine providers but to the federal government. ${ }^{17}$ There were roughly 500 GBS victims among the vaccinated and a similar number among the unvaccinated. About 4,000 claims were filed against the federal government as a result of the swine flu campaign, alleging four billion dollars in damages. ${ }^{18}$ One of the claims-Manko-is the topic of the next section.

\section{III}

\section{THE MANKO CASE}

In Manko, the plaintiff used relative risk to demonstrate specific causation. ${ }^{19}$ The case was well argued, with a solid basis in epidemiology. Still, the proof is unconvincing. The evidence will be reviewed in some detail to show the strengths and weaknesses of the relative-risk approach. Louis Manko was vaccinated on October 20, 1976, and developed symptoms of "smoldering GBS" within a week or two, including lightheadedness, tingling sensations, and weakness in his limbs. ${ }^{20}$ Around January 15, 1977, he was hospitalized with acute GBS. $^{21}$ The federal government refused compensation, on the basis that his "smoldering GBS" was not GBS, and his acute GBS developed too long after he was vaccinated for causation to be probable. ${ }^{22}$ Manko sued and the court ruled in his favor, adopting two theories of specific causation. ${ }^{23}$ First, if "smoldering GBS" is indeed GBS, then causation follows from the epidemiologic evidence; and second, if plaintiff contracted GBS in mid-January 1977, some

15. Here we differ with Langmuir et al. On our reckoning, the relative risk for cases of type C-D-E is about seven in the first week after vaccination, with a fairly smooth decline to background levels by the eleventh week. See supra note 12 for the classification.

16. The National Influenza Immunization Program of 1976 ("Swine Flu Act"), Pub. L. No. 94-380, 90 Stat. 1113 (codified at 42 U.S.C. $\$ 247$ (b) (1976) (repealed 1978)), provided that claims were to be brought under the Federal Tort Claims Act, 28 U.S.C. $\$ \$ 1346(b) ~(1976), 2671-2680$ (1994).

17. For current legal procedures for handling vaccine-related injuries, see MOLLY TREADWAY JOHNSON ET AL., USE OF EXPERT TESTIMONY, SPECIALIZED DECISION MAKERS, AND CASEMANAGEMENT INNOVATIONS IN THE NATIONAL VACCINE INJURY COMPENSATION PROGRAM (1998).

18. See SilversteIn, supra note 6, at 127; Langmuir et al., supra note 7, at 842; Neal Nathanson \& E. Russell Alexander, Infectious Disease Epidemiology, 144 AM. J. EPIDEMIOLOGY S34, S37 (1996); The total number of GBS cases was computed by us from data in Langmuir et al. 1987).

19. Manko v. United States, 636 F. Supp. 1419 (W.D. Mo. 1986), aff'd in part, 830 F.2d 831 (8th Cir.

20. See id. at 1429.

21. See id. at 1431.

22. See id. at 1433.

23. See id. at 1427. 
thirteen weeks after vaccination, specific causation still follows because the relative risk for such late-onset cases is well above the threshold value of $2.0 .^{24}$

The arguments on causation for late-onset $\operatorname{cases}^{25}$ are the most interesting. Plaintiff introduced expert testimony from Nathan Mantel and Martin Goldfield. ${ }^{26}$ Mantel was a well-known biostatistician at the National Institutes of Health. Goldfield was the county medical officer who worked on the Fort Dix outbreak; he was one of the first to identify the disease as influenza and one of the first to advise against mass vaccination. Defendants' epidemiology experts were Leonard Kurland of the Mayo Clinic and Neal Nathanson of the Pennsylvania Medical School, ${ }^{27}$ they were coauthors of the "Langmuir report." 28 Langmuir was the founder of the Epidemiologic Investigative Service at the CDC.

Panel (a) in Figure 1-essentially the case for the defense on late-onset GBS - shows only a small excess risk after the eighth week. However, Goldfield and Mantel argued that to compare like with like, it was necessary to "stratify" on time of vaccination and time since vaccination when computing relative risks (stratification will be explained below). The rationale was ingenious: They hypothesized a decrease in reporting of vaccinated GBS cases, parallel to the decline in reporting of the unvaccinated cases.

As discussed in Part I, relative risk compares the observed number of GBS cases with the number expected on the theory that vaccination does not cause GBS:

$$
\mathrm{RR}=\text { Observed/Expected }
$$

Goldfield and Mantel computed the expected numbers for each week from vaccination to onset, separately for each vaccination cohort-those vaccinated in week one, those vaccinated in week two, and so forth. Finally, they summed the contributions from the various cohorts to get the expected number of cases in each week after vaccination. ${ }^{29}$ In effect, this synchronizes the two time scales in Figure 1.

Goldfield and Mantel used the raw (untruncated) background rates to compute the relative risk, as in Figure 2(a). Late-onset cases are now being compared to the very small number of background cases reported after the moratorium, and the relative risk is large. ${ }^{30}$ For comparison, panel (b) in Figure 2

24. See id. at $1434,1437$.

25. See id. at 1433-37.

26. See id. at 1433 n. 4 .

27. See id. at 1433 n.5.

28. See Langmuir et al., supra note 7.

29. See Freedman \& Stark, supra note 5, app. B. Separating the contributions from the various cohorts is an instance of what epidemiologists call "stratification." The observed number of cases is not affected by stratification, but the expected number is, because the background rates used in the calculation depend on time.

30. Since the raw background rate is low after the moratorium, the expected number of cases will be low in that time period, and the ratio of observed to expected (that is, the relative risk) will be correspondingly high. 
shows relative risks computed by the Goldfield-Mantel procedure, stratifying both on time of vaccination and time since vaccination, but with background rates truncated at 0.24 per million person-weeks of exposure. The threshold relative risk of 2.0 is marked by dashed horizontal lines. There were no cases in the fourteenth week after vaccination, only four in the fifteenth week, and one in the sixteenth week. The tail of the curve is quite shaky, so plaintiff's experts pooled the data for weeks eleven through sixteen as indicated by the solid horizontal lines in both panels. ${ }^{31}$

FIGURE 2: Relative risk for GBS among the vaccinated, plotted by time since vaccination. Panel (a) shows the Goldfield-Mantel analysis, with stratification by time of vaccination as well as time since vaccination; raw background rates are used. Panel (b) stratifies the same way, but background rates below 0.24 per million person-weeks are replaced by 0.24 (truncation). The short horizontal line pools the data in weeks $11-16$, to stabilize the estimates.

Both panels in Figure 2 use the same observed numbers and compute expected numbers the same way, except for truncation. The issue is not stratification but truncation, and the crucial question is this: Was there a drop in reporting of vaccinated GBS cases after the moratorium, parallel to the drop in background rates? If so, Figure 2(a) is persuasive and the relative risk for lateonset cases is well above 2.0. If not, panel (b) is the one to use and excess risk is minimal.

31. See Manko, 646 F. Supp. at 1436. 
(A) RAW BACKGROUND RATES

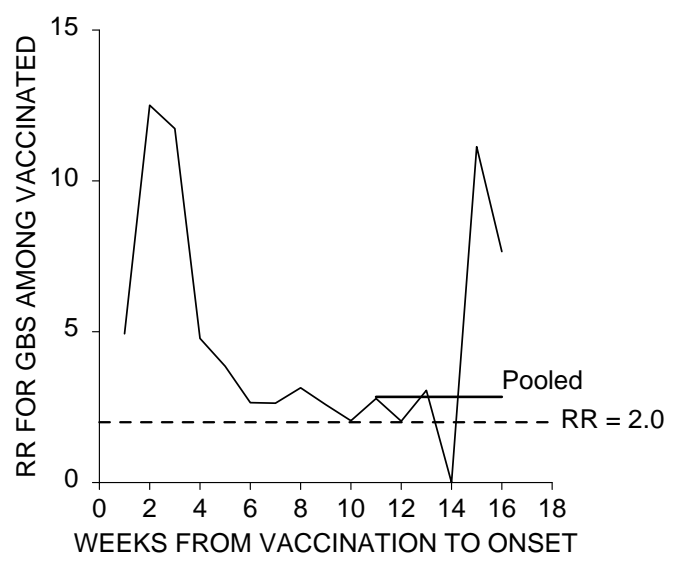

(B) BACKGROUND TRUNCATED AT 0.24

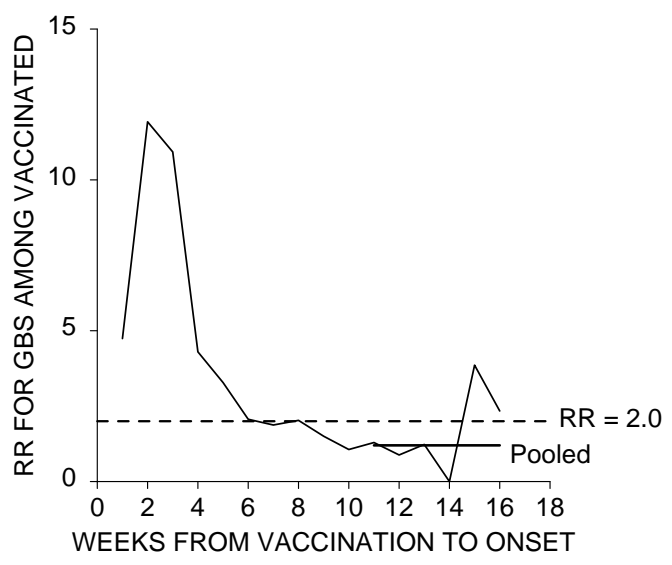




\section{A. Completeness of Reporting}

Both sides in Manko agreed that the drop in background rates was artifactual. $^{32}$ The issue was the plaintiff's hypothesis of a parallel drop in reporting of vaccinated cases. To validate that hypothesis, Goldfield and Mantel compared the incidence rate of GBS among the vaccinated before and after the decline in background rates. ${ }^{33}$ However, the numbers are small. Moreover, a real decline in the incidence rate is only to be expected, because the attack rate decreases with time since vaccination (Figure 1), and most vaccinations occurred fairly early in the sequence of events. Thus, it is not easy to demonstrate a decline in reported incidence rates over and above the expected real decline, although the idea may have merit. ${ }^{34}$

To address the completeness of reporting, Langmuir et al. compared attack rates for three cohorts-persons with early, middle, and late vaccinations- the idea being that a decline in reporting rates would affect the late cohort significantly more than the early or middle cohort. ${ }^{35}$ They saw no evidence for a decline in reporting rate among vaccinated GBS cases. ${ }^{36}$ A priori, such a decline seems implausible. Vaccination by itself could have made a diagnosis of GBS more likely, because vaccination was seen as a leading cause of GBS. Moreover, reporting is likely to be more complete among the vaccinated cases than the unvaccinated, because vaccinated cases generally had to be reported to the federal government for victims to claim compensation. ${ }^{37}$

For an empirical test, following Goldfield and Mantel, we "smoothed" the relative risks in Figure 2(b) to make the curve decline more slowly and regularly after the first four weeks. The objective was to reduce the impact of chance fluctuations and potential misreporting. The smoothed curve was then used to estimate the likely number of post-moratorium GBS cases among the vaccinated. Although specific results depend on the smoothing, the reporting of vaccinated GBS cases seems to have dropped after the moratorium by no more than twenty percent. There also seems to have been over-reporting for a couple of weeks just prior to the moratorium, which suggests that onset dates were advanced by a week or two in the CDC's database around that time. ${ }^{38}$ If the rela-

32. See Goldfield, Trial Transcript, vol. 6 at 44, Manko v. United States, 636 F. Supp. 1419 (W.D. Mo. 1986) (No. 79-1011-CV-W-9) (for the plaintiff); Langmuir et al., supra note 7, at 856 (for the defense). Nathanson states the issue quite clearly in the Trial Transcript, vol. 18 at 113-15, Manko (No. 79-1011-CV-W-9). However, the court found "no significant decline in reporting cases of GBS after the moratorium." See Manko, 636 F. Supp. at 1435.

33. See Trial Transcript, vol. 6 at 61-67, Manko (No. 79-1011-CV-W-9).

34. See Schonberger et al., supra note 7, fig. 1; see also Langmuir et al., supra note 7, tbl. 5. See generally Henry F. Retailliau et al., Illness After Influenza Vaccination Reported Through a Nationwide Surveillance System, 1976-1977, 111 AM. J. EPIDEMIOLOGY 270 (1980).

35. See Langmuir et al., supra note 7, at 861-66.

36. See id.

37. Cf. James S. Marks \& Thomas J. Halpin, Guillain-Barré Syndrome in Recipients of A New Jersey Influenza Vaccine, 243 JAMA 2490, 2493 (1980).

38. See Freedman \& Stark, supra note 5, app. B. Since most vaccinations occur fairly early and most cases among the vaccinated occur soon after vaccination, the details of the smoothing do not have a major impact on results. 
tive risk for late-onset GBS in the right hand panel of Figure 2 is biased downward, the effect is small. Indeed, current medical literature does not support the hypothesis of swine flu vaccination as a cause of late-onset GBS. ${ }^{39}$

\section{B. Discovery Issues}

In pre-trial discovery proceedings, the federal government declined to produce the CDC's detailed medical records on GBS victims. ${ }^{40}$ For some of these cases, critical information on the date of vaccination or the date of onset of GBS was missing in the summary sheets that were made public and used both by the plaintiffs and the defense. To resolve this discovery issue, the court imposed an information sanction. Langmuir et al. had excluded from their analyses some twenty-eight cases with missing data. ${ }^{41}$ The plaintiff's experts were allowed to count eight of these cases as having late onset. ${ }^{42}$

\begin{tabular}{lrr}
\hline & \multicolumn{1}{c}{ Raw } & \multicolumn{1}{c}{ Truncated } \\
\hline Extensive cases & $9 / 4.41=2.04$ & $9 / 10.2=0.88$ \\
All cases & $21 / 7.40=2.84$ & $21 / 17.5=1.20$ \\
Sanctions & $29 / 7.40=3.92$ & $29 / 17.5=1.66$ \\
\hline
\end{tabular}

TABLE 1: Relative risks for GBS cases, with onsets in weeks eleven to sixteen after vaccination. $\mathrm{RR}=$ Observed/Expected. The first column computes the "expected" using the raw background rates. The second column truncates the background rate at 0.24 per million person-weeks. Row 1 shows data for cases with extensive paralysis; row 2, for all cases; row 3 adds eight cases to the numerator, as a consequence of sanctions imposed by the court on defendants. The Goldfield-Mantel stratification procedure is used throughout.

Table 1 shows the relative risk for GBS with onset eleven to sixteen weeks after vaccination, computed on various sets of assumptions. The GoldfieldMantel stratification procedure is used to compute all the expected values and relative risks in the table. When background rates are truncated, stratification

39. See HUGHES, supra note 10, at 102; ROPPER ET AL., supra note 10, at 28-29, 57; Hahn, supra note 10 , at 636

40. The government took the position that there were binding nationwide discovery rules, which did not require production of the disputed records. The trial court disagreed, and the appeals court declined to review that issue. See Manko v. United States, 830 F.2d 831, 834-35 (8th Cir. 1987).

41. See Langmuir et al., supra note 7, tbl. 1. Langmuir et al. began with about 1300 case reports; 100 were excluded because onsets fell outside the study period; another 100 were excluded for reasons that are not made clear. See id. at 843. Reasons for other exclusions are detailed in the table, for example, vaccination was recommended only for persons over the age 18, and 121 cases were below that age.

42. According to the sanction, plaintiff's experts were allowed to fill in the missing dates any way that did not contradict other information on the summary sheet. Certain other ambiguities could also be resolved in favor of plaintiff's statistical theories. See Manko, 636 F. Supp. at 1438, 1453 (sanctions); $i d$. at 1436-37 (on the calculation of relative risk). We infer the figure of eight additional cases to reconcile the numbers in notes 10 and 11 of the opinion with the data in Langmuir et al. See id. 
and discovery sanctions only bring the relative risk up to 1.66. As the table confirms, stratification is a side-show; the critical issue is the truncation used to correct for incomplete reporting. ${ }^{43}$

The table also shows that relative risk depends on severity of illness: With late-onset GBS, paradoxically, relative risk is lower for severe cases. In general, relative risk in an epidemiological study is the average of relative risks for various subgroups. Differences are to be expected, and that is the topic of the next section.

\section{Individual Differences}

Prior infection is a risk factor for GBS. About sixty-two percent of the unvaccinated GBS cases had some illness in the month before onset; for the vaccinated cases, only thirty-three percent had prior illness. ${ }^{44}$ A somewhat informal calculation $^{45}$ suggests that prior illness multiplies the relative risk by about $33 \% / 62 \%=0.53$. Manko had an infection with respiratory and gastro-intestinal symptoms a week or two before his hospitalization for acute GBS. ${ }^{46}$ Multiplying the relative risk of 3.92 by 0.53 brings it very close to the critical value of 2.0. However, Goldfield and Mantel argued that the 0.53 includes a selection effect, because people are advised against vaccination immediately following illness. To avoid the selection effect, Goldfield and Mantel based the numerator of their correction only on the late-onset GBS cases among vaccinated persons, where fifty-three percent were preceded by illness, ${ }^{47}$ the relative risk should now be multiplied by $53 \% / 62 \%=0.85 .^{48}$

The number of late onset cases is rather small (Table 1), and the experience of this group should probably not be compared to all unvaccinated cases, but only to cases with onsets in a similar time period, namely late December and early January. The pattern of respiratory infections, for example, is seasonal (in contrast with the pattern of background GBS). Plaintiff's argument is therefore not wholly convincing. Current literature confirms that about two-thirds of GBS cases are triggered by previous illness. ${ }^{49}$ With respect to one pathogen-

43. The numbers in the table are computed by us from data in Langmuir et al., supra note 7. For details, see Freedman \& Stark, supra note 5, app. B. For the classification of cases by extent of paralysis, see supra note 12.

44. See Schonberger et al., supra note 7, at 116; Langmuir et al., supra note 7, at 663.

45. This calculation is like the one used by plaintiff's experts Goldfield and Mantel and starts from Bayes' rule; it is reconstructed in Freedman and Stark, supra note 5, app. B.

46. See Plaintiff's Exhibit 401, Manko v. United States, 636 F. Supp. 419 (W.D. Mo. 1986) (No. $79-$ 1011-CV-W-9).

47. See Trial Transcript, vol. 7 at 39, Manko (No. 79-1011-CV-W-9).

48. In Manko, 636 F. Supp. at 1419 n.12, the multiplier is given as 0.87. Different experts-even on the same side-seem to have been using slightly different versions of the CDC database. And there is an annoying numerical coincidence, as 0.53 crops up twice with two different meanings.

49. See, e.g., Hughes, supra note 10, at 106; ROPPER ET AL., supra note 10, at 57; Hahn, supra note 10 , at 636 . 
Campylobacter jejuni, which causes gastrointestinal symptoms-the molecular basis for subsequent GBS is now reasonably well understood. ${ }^{50}$

Age is another factor to consider. Manko was sixty-four years old at vaccination. $^{51}$ That would reduce the relative risk by perhaps twenty-five percent, if it is fair to average across onset times. ${ }^{52}$ Finally, the clinical course of the disease should be mentioned. About ninety-five percent of patients reach their nadir within a month of onset, and roughly seventy percent recover completely within a year. ${ }^{53}$ In this respect too, Manko was quite unlike the bulk of the GBS victims ${ }^{54}$ so data about them may not help very much in deciding the cause of his injury. These arguments apply as well to smoldering GBS, although the issues in court turned more on the medical definitions. Manko was a well-argued case with a solid empirical base, thoroughly reported in the epidemiologic literature. Even so, the proof of specific causation, starting from a relative risk of four, seems unconvincing. ${ }^{55}$ That gives us pause, and the issue goes well beyond Manko.

IV

\section{SUMMARY AND CONCLUSIONS}

The scientific connection between specific causation and a relative risk of 2.0 is doubtful. If the relative risk is near 2.0, problems of bias and confounding in the underlying epidemiologic studies may be serious, perhaps intractable. Problems created by individual differences may be equally difficult. Bias and confounding affect the estimation of relative risk from the underlying data. By contrast, individual differences affect the interpretation of relative risk, namely, the application to any specific individual.

With Manko, at least in retrospect, it is difficult to establish an elevated relative risk for late-onset cases. Moreover, the plaintiff is in crucial detail remarkably unlike the other GBS victims. So the connection between him and the data stays rather loose. Mathematical models show how the effect of individual differences can be represented in a more general-but more abstract-

50. See Irving Nachamkin et al., Campylobacter Species and Guillain-Barré Syndrome, 11 Clinical Microbiology ReV. 555 (1998); see also Arthur K. Asbury, New Concepts of GuillainBarré Syndrome, 15 J. CHILd NeurologY 183 (2000); Richard A.C. Hughes et al., Pathogenesis of Guillain-Barré Syndrome, 100 J. Neuroimmunology 74 (1999). Among other things, these papers indicate that GBS comprises several different diseases, each with a characteristic etiology.

51. See Plaintiff's exhibit 401, Trial Transcript, vol. 16 at 193, Manko v. United States, 636 F. Supp. 1419 (W.D. Mo. 1986) (No. 79-1011-CV-W-9).

52. See Lasky et al., supra note 10, tbl. 1; Schonberger et al., supra note 7, at 114.

53. See Hughes, supra note 10, at 122-23; Hahn, supra note 10, at 639; cf Manko, 636 F. Supp. at 1427.

54. As noted supra, Manko contracted a mild form of the illness within a week or two of vaccination; his condition gradually deteriorated, and acute illness struck three months later. Even at the time of trial-seven years after vaccination-he was severely incapacitated. See Manko, 636 F. Supp. at $1429,1441$.

55. See Table 1 (showing a relative risk of 3.92). The opinion quotes the relative risk as 3.89. See Manko, 636 F. Supp. at 1437. 
[Vol. 64: No. 4

setting. ${ }^{56}$ The results confirm one of the central points about Manko: Epidemiologic data cannot determine the probability of causation in any meaningful way because of individual differences.

56. See Freedman \& Stark, supra note 5, app. A (discussing the impact of individual differences on the probability of specific causation). 